\title{
Project and disaster risk management under climate change
}

\author{
G. Nhamo \\ Institute for Corporate Citizenship, University of South Africa, \\ South Africa
}

\begin{abstract}
Very few decision markers now dispute the challenges associated with climate change (CC). The world over, CC awareness has risen to undisputed levels and this will continue to be so in the few decades to come. However, challenges still remain in terms of understanding and a need to integrate $\mathrm{CC}$ within the context of developmental tools like project planning (PP), disaster risk management (DRM) and environmental evaluation (EE) when dealing with brownfields development. The situation is aggravated by the fact that very few (if at all) professionals involved in decision making and development planning have formal tertiary education and training incorporating the four areas under discussion. Among the decision makers are: the chief executive officers, politicians, town planners, engineers, financiers, economists, project managers and consultants. Times have changed and the business of today requires that decision makers at all levels have adequate knowledge and awareness on the reality of $\mathrm{CC}$ and how this must be mainstreamed into decision making tools like PP, DRM and EE. This paper presents theoretical perspectives and conceptualises a framework in which CC could be mainstreamed into PP, DRM and $\mathrm{EE}-$ a four-in-one framework when dealing with brownfield issues. The work is a valid information source for the group of practitioners indentified and other interested stakeholders. The paper establishes and concludes that CC issues in brownfield development, particularly mitigation, adaptation and technology can be better addressed through the proposed four-in-one framework. Such a framework is made possible by existing synergies in PP, DRM and EE cycles. This is an aspect that could assist, especially developing countries to move fast towards green, low-carbon economies and be part of the global greening evolution.
\end{abstract}

Keywords: brownfield development, climate change, project planning, disaster risk management, environmental evaluation, four-in-one framework. 


\section{Introduction}

Is it happening or not? Is the science correct? These are the questions that dominated the climate change (CC) space in the last one and a half or so decades of the $20^{\text {th }}$ century. Today, this space has been closed significantly and a global consensus has emerged. Both the science and devastating realities of the changing climate have been accepted as real. In addition, an urgent need to address $\mathrm{CC}$ in all decision making processes at all levels ranging from the very local, through national, continental and global scales has been raised on both the political and economic agendas. The dominant questions today are: What must be done about global warming and $\mathrm{CC}$ and how best can we address it? Are we doing enough? If not, what more can we do?

On the developmental front, the global warming and $\mathrm{CC}$ discourse has changed patterns in decision making and calls have been made for a need to integrate $\mathrm{CC}$ in major decision making tools that include project planning (PP), disaster risk management (DRM) and environmental evaluation (EE), including environmental impact assessment (EIA). This paper focuses on discussing how $\mathrm{CC}$ issues can be incorporated into the three decision making tools identified through the proposed four-in-one framework. The proposed framework must be popularised through tertiary, in-service and other education and training platforms for key decision makers that include among them chief executive officers, politicians, town planners, engineers, financiers, economists, project managers and consultants.

\section{Overview on CC, natural disasters and economic loss}

In its Fourth Assessment Report of 2007, the Intergovernmental Panel on Climate Change (IPCC) predicts the following phenomena and direction of trend in weather and climate events FAO [1, p.3]:

- Warmer and fewer cold days and nights; warmer and more frequent hot days and nights over most land areas (virtually certain)

- Warm spells and heat waves increasing in frequency over most land areas (very likely)

- Heavy precipitation events increasing in frequency over most areas (very likely)

- Drought-affected area increases (likely)

- Intense tropical cyclone activity increases (likely)

- Extremely high sea levels increase in incidence (excludes tsunamis) (likely).

The changing climate is caused by human induced greenhouse gases (GHGs), chief among them carbon dioxide. Other GHGs include among them, methane and nitrogen oxide. It is also necessary to know the key sources of such GHGs. These include agriculture (14\%), residential and commercial activities (8\%), transport (13\%), deforestation (17\%), waste and wastewater $(3 \%)$, industry $(19 \%)$, and energy (26\%). The energy supply and industry sectors contribute the 
largest share of GHGs with a combined total of 45\% IPCC Working Group II [2]. Agriculture also takes up a significant portion. The goal of Article II of the United Nations Framework Convention on Climate Change (UNFCCC) outlines the need to ensure the stabilisation of GHG concentrations in the atmosphere at a level that would prevent dangerous anthropogenic interference with the climate system. Such a level "should be achieved within a time-frame sufficient to allow ecosystems to adapt naturally to climate change, to ensure that food production is not threatened and to enable economic development to proceed in a sustainable manner" FAO [1, p.1].

Globally, weather and CC-related disasters have quadrupled since the late 1980s and over the same period the number of people affected by disasters has increased from around 174 million to an average of over 250 million a year Oxfam [3]. Oxfam also records that between 1980 and 2006, the number of floods and cyclones quadrupled from 60 to 240 a year globally and Chafe [4] indicates the following figures in terms of deaths from weather-related disasters in 2006: floods $(6,020$ people), extreme temperatures $(4,090)$, windstorms $(4,420)$, landslides and avalanches $(1,650)$ and wildfires $(20)$. Such losses are also accompanied by economic and insured losses as shown in Figure 1. It is such loses that include both human life and money that our generation views CC as a real threat that needs urgent redress and integration into key development and decision making tools.

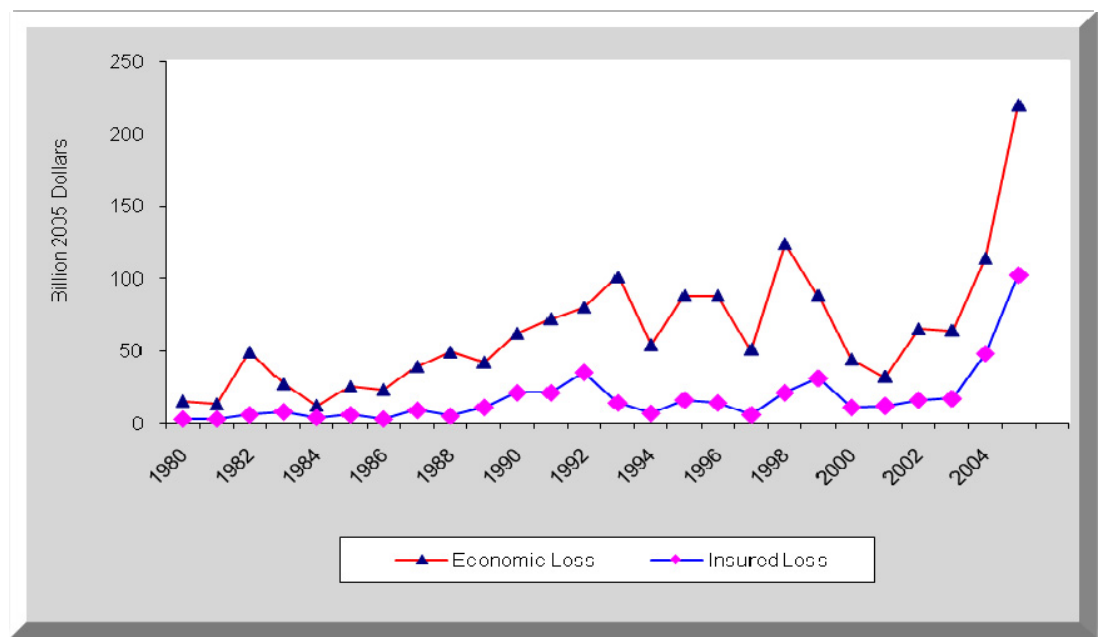

Source: Author after Munich Re data cited in Chafe [4, p.45].

Figure 1: Economic and insured loss from weather-related disasters (19802006). 


\section{Project planning, disaster management and environmental evaluation}

The project management cycle provides multi opportunities Swiss Agency for Development Cooperation [5] upon which decision makers can integrate disaster risk management and environmental evaluation to prevent project failure during times of crisis. It is therefore paramount to note from the onset that disaster risk management incorporates weather and climate oriented disasters. In fact, a generic identification of disasters includes the binary distinction between those that are natural and those that are human-induced. A cyclical orientation in project planning can be identified and although different authors specify different stages in the cycle Caribbean Development Ban [6], ProVention Consortium [7], USAID [8], those presented in Figure 2 are common and generic. The four stages cited in the Figure 2 include: identification, preparation and design, financing and implementation as well as evaluation. Since the subject of this paper looks at a four-in-one framework, Figure 2 has been conceptualised in a manner that allows the integration of $\mathrm{CC}$ aspects into the project planning cycle.

From Figure 2, decision makers should be aware of simple measures that one can keep at the back of their mind in terms of weather and climate oriented issues. For example, during the project identification stage, one could check for climate disaster risk reduction potential. During project preparation and design stage one could look at improving climate resilience. At project financing and implementation, decision makers must monitor the development of climate risks and the inclusion of climate risk reduction. When evaluating the project one could assess the behaviour of the project under CC oriented stress and whenever possible implement climate mitigation and adaptation measures.

In as much as the project planning and management cycle looks simplified in Figure 2, there is complexity, accompanied by contestations in each one of the stages cited. In fact, decision makers must always consider the identified stages as mini, sub-cycles in their own right that have inherent complexity and contestations too. There is going forwards and backwards as decisions are taken at each of these mini, sub-cycle phases that influence both past and future decisions in the project cycle. Another critical aspect to bear in mind is the need to view the entire project cycle in a web-like manner that allows decision makers to move across stages in a networked fashion resulting in lateral, vertical and diagonal patterns. Many decision makers have fallen trap to follow the generic project cycle stages in a neatly laid out linear manner resulting in poor decision making. The outer boxes highlighting $\mathrm{CC}$ aspects as provided in Figure 2 also bring new perspectives to the project cycle stages.

At another related level, EE (including environmental impact assessment EIA) has been one of the most favoured decision making tools when evaluating development projects, especially for sustainability purposes. The EIA is seen as enabling development to be in harmony with the ecological and human systems. As a tool, an EIA mitigate against negative impacts of a proposed development (be it a project, programme or policy). It is therefore important that decision 


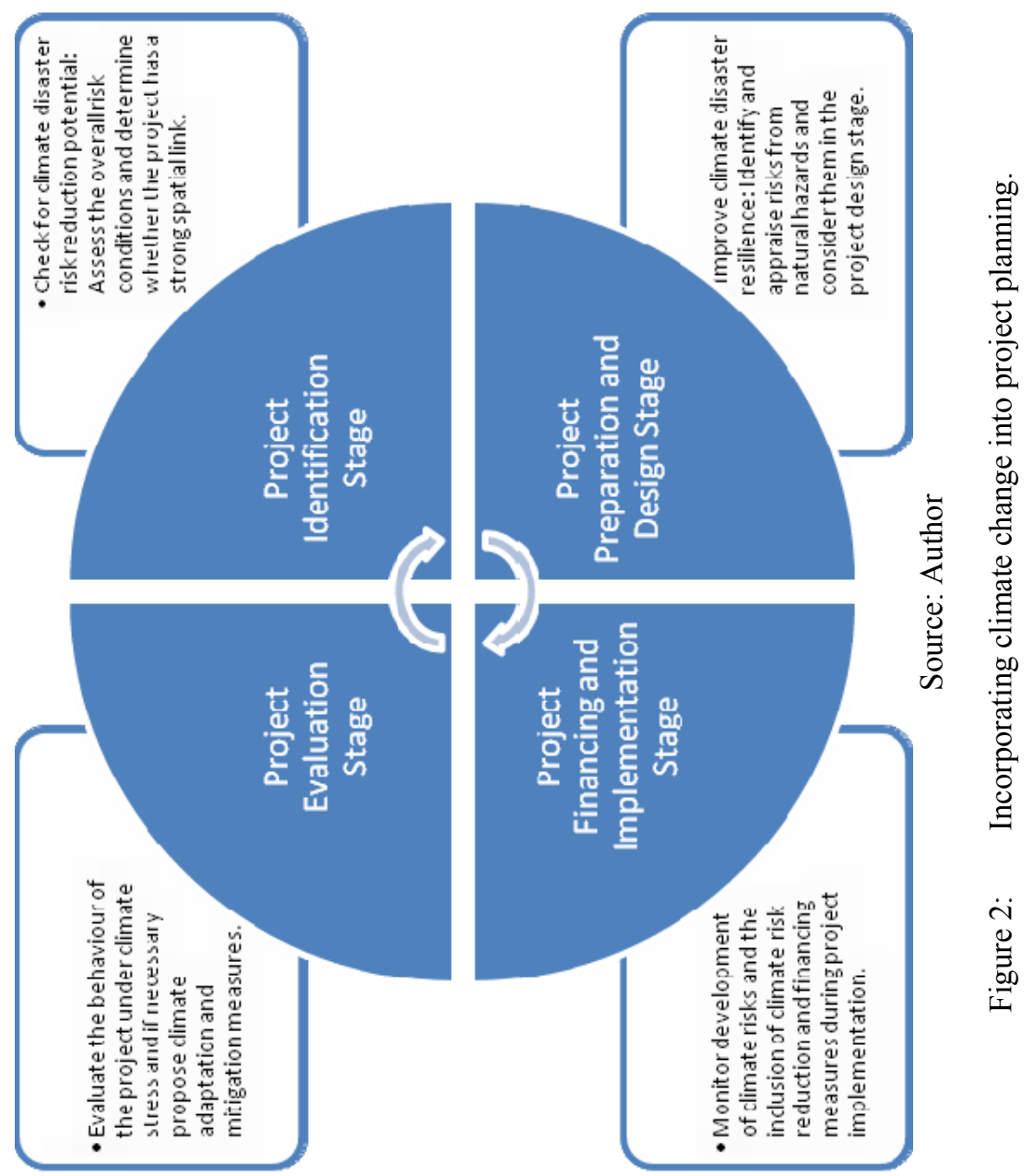


makers consider $\mathrm{CC}$ issues when evaluating projects, programmes and policies. This means that at any given stage of the EIA cycle associated $\mathrm{CC}$ issues should be considered as an integral part to decision making including the identification and quantification of GHG emissions.

The generic natural hazards-EIA flow chart presented in Figure 3 is of use when considering disaster risk (including climate change) management and EIA. After defining the project and its alternatives (Step 1), decision makers must be alerted of the preliminary climate hazards leading to climate vulnerability mapping (Larsen and Springer [9]) and assessment (Step 2). Following the preliminary climate hazard mapping and assessment, screening could take place leading to a much more detailed scoping exercise related to environmental and climate related impacts for the proposed project (Steps 3-4). At this point, either a full EIA or scoping level EIA could be done that includes not only the identification of general environmental impacts (both positive and negative) but also specific weather and climate related impacts. Decision makers should be fully informed of the need to mitigate against and adapt to weather and $\mathrm{CC}$ related impacts including the necessary technologies and financing mechanisms. Aspects pertaining to research and development within the four key pillars in addressing CC namely: mitigation, adaptation, technology and financing also require attention.

If a full scale EIA is determined then the assessment and evaluation of environmental, weather and climate related impacts will be done (Step 5). During this phase decision makers must be made aware of the baseline, predicted impacts, evaluated options and mitigation measures in terms of the general environmental evaluation. With specific reference to weather and climate oriented impacts additional information should be given concerning the manner in which the project can be made to adapt to the changing weather and climatic conditions as well as resultant disasters and hazards. This lag would also address technology, financing as well as research and development. During the same phase, decision makers should be in the picture with regard to the selection of the preferred project alternatives based on the holistic environmental, weather and climate related impact identification, prediction and evaluation. Such information will lead to a decision being taken concerning the feasibility of the proposed development project.

Steps 6 to 10 (Figure 3) would then concentrate on project design. During this design phase decision makers should be equipped with a comprehensive environmental management plan (Step 6). This plan is different from the old type plan in a purely EIA venture as it must fully integrate weather and climate related concerns including both short, medium and long-term disaster risk mitigation and adaptation. Such a plan should outline how relevant government departments and other interested and affected parties can address weather and climate related disasters in the event of them happening. Aspect such as climate risk insurance (including index or weather insurance) may be outlined in depth depending on the nature of the project, programme or policy assessed. A monitoring programme must also form part of the decision making process (Step 8) as this and other documentation is finalised into a comprehensive 


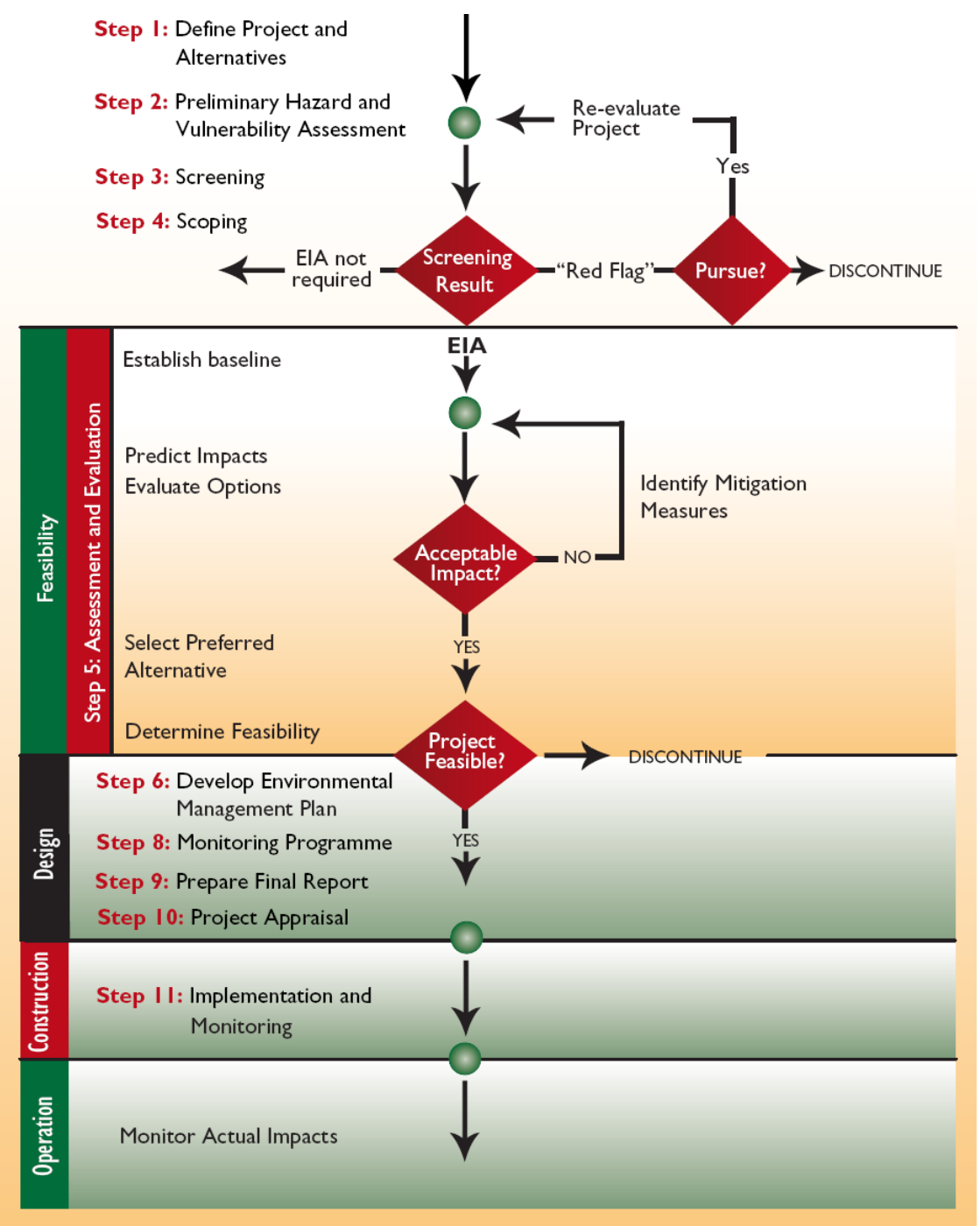

Source: Caribbean Development Bank [6, p.9].

Figure 3: Generic natural hazards - EIA flow chart.

environmental and disaster (including weather and climate) assessment report for the proposed development project (Step 9).

The management plan can be utilised during the design stage in mitigating against adverse weather and climate oriented impacts. The designs could also be made to adapt to weather and climate oriented impacts. For example, if it is a project in a flood prone zone, flood proofing could be incorporated and flood zones strictly observed. Undevelopable areas (as determined by the nature of the 
proposed development) could be left open and used for non-permanent structures such as parks and other open areas. This is an area traditionally dominated by town and regional planners. The decision makers would then be expected to appraise the proposed development project and make a decision to invest or not (Step 10). The weather and climate information forming part of the so-called upgraded EIA report will be fundamental in the appraisal phase.

The next stage will be construction (if it is a project with specific location) or implementation (if it is a programme or policy without an immediate location). During construction, implementation and monitoring is required (Step 11). Monitoring will be done using the management plan and the final upgraded EIA report. What will be critical here is to mitigate against the negative weather and climate oriented impacts and enhance positive impacts. Decision makers also require information on the actual monitoring of weather and climatic patterns. Early warning systems (possibly as incorporated into the management plan) will be activated and whenever required, re-designed.

During the operation phase of the project aspects related to greenhouse gas (GHG) emissions will be of interest. Although some mitigation could have been done from the management plan, for example, through specifying a need to capture and store carbon as well as incorporating this specification into the project design, decision makers still need to monitor the actual specifications during operation. Reducing the carbon footprint through latest technologies like carbon capture and storage (CCS) remains an ongoing research and development issue. The South African Long Term Mitigation Strategy DEAT [10], for example, specifies CCS as one of the technologies to be used in transition to low carbon economy. Coal-fired power stations, petroleum refineries and other heavy GHG emitting plants and projects are subject to the CCS policy. Other mitigation measures that could be specified in the management plan might include use of alternative energy sources like solar and wind. Energy efficiency could also be stipulated and all these could be integrated in the project design at appropriate stages.

\section{Towards a four-in-one framework}

The proposed four-in-one framework integrating CC into PP, DRM and EE requires that practitioners view the four areas under consideration simultaneously. A planner or any other decision maker is required to have this holistic picture in order to adequately assess risks associated with $\mathrm{CC}$ with the valuable application of decision making tools as mentioned above. The four-inone framework therefore challenges decision makers to be multidisciplinary in thinking and possibly training. It challenges linear, discipline oriented thinking and brings in the concept of network, web-oriented thinking when addressing CC in the context of development, projects and DRM. The framework then challenges the conventional way in which education and training is done. It implies that decision makers receive adequate knowledge and training in the four key disciplines so that they become flexible and adaptive resources. This is not a 
once off or overnight proposal, but a carefully thought out, continuous improvement approach.

The four-in-one framework challenges those in tertiary and in-service training institutions to re-think their curricula and offer both life-long and relevant educational packages that are climate compliant. Such is the nature of decision makers the $21^{\text {st }}$ century demands. A simplified conceptual framework for the four-in-one framework is presented in Figure 4.

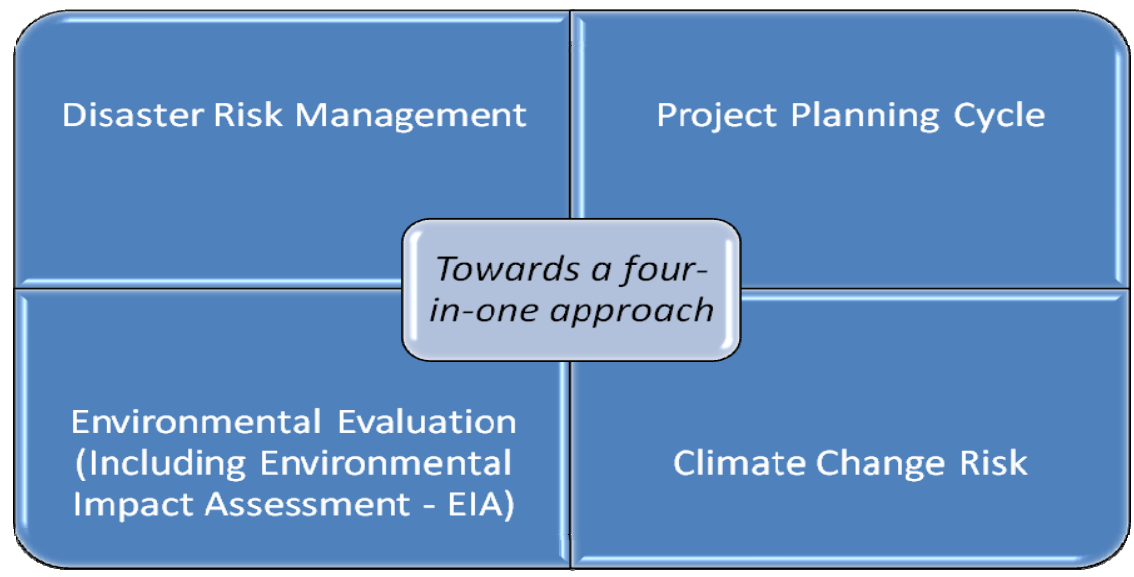

Source: Author

Figure 4: A four-in-one conceptual framework.

Given that many decision makers today did not undergo formal education and training in the disciplines related, particularly to $\mathrm{CC}$; it is inevitable that more and more in-service top-up training be conducted if we are to engage favourably with the CC phenomenon. Over the years, there has been evidence of overloaded, bureaucratic procedures in the three cycles under discussion - PP, DRM and EE, yet there are inevitable linkages that can be exploited. Collapsing the processes associated with these cycles into one that is enhanced by fusing CC in it certainly makes greater sense. It is not only effective but also efficient in propelling development.

The global warming and $\mathrm{CC}$ discourse is complex and heavily politicised. This means that apart from the need to master the four core areas under consideration here, decision makers must prepare themselves in engaging politicians and politics. One such arena concerns the climate negotiations, a platform where the global agenda on $\mathrm{CC}$ is set. By the time of writing this paper, climate negotiations were taking place in Copenhagen (December 2009) and heavy contestations emerged. At one stage, the African group boycotted for a day preparatory negotiations that took place in October 2009 in Barcelona, Spain. Such is the nature of the complexity surrounding the global warming and $\mathrm{CC}$ discourse. 
Overall, for the four-in-one framework to be effective and efficient, a call is made to revolutionalise government policy and laws, especially in town and regional planning. A lot of government policies governing PP, DRM and EE have been done outside the $\mathrm{CC}$ epoch. Hence these are rather outdated. Municipal building by-laws still remain the pivotal entry point to mitigating and adapting to $\mathrm{CC}$ and issuance of both the development permits (or certificates) and building occupancy certificates could be a proper intervention point to redress the impacts of CC. Solar water heating, flood plain management and energy efficiency and green buildings by-laws could be some among a myriad of by-laws that can be implemented.

\section{Conclusion}

This paper presented theoretical perspectives and conceptualised a framework in which climate change (CC) could be mainstreamed into PP, DRM and EE when dealing with brownfield developmental issues. The resultant conceptual framework - a four-in-one approach was popularised for decision makers from various professions. The paper argued that decision makers have major challenges in terms of understanding and integrating $\mathrm{CC}$ into decision making and developmental tools that include PP, DRM and EE. This is a situation, the paper proposed, aggravated by the fact that very few (if at all) of these decision makers undertook formal tertiary education and training incorporating the four areas under discussion. Among the decision makers of concern were highlighted chief executive officers, politician, town planners, engineers, financiers, economists, project managers and consultants. The proposed four-in-one framework is viewed as a valid information source for the group of practitioners identified and other interested stakeholders. The paper also proposed that the proposed four-in-one framework could assist, especially the developing countries to move fast towards green, low-carbon economies and be part of the global greening evolution.

\section{Acknowledgement}

The author thanks Exxaro Resources Limited for sponsoring the Chair in Business and Climate Change run under Unisa's Centre for Corporate Citizenship.

\section{References}

[1] FAO. Climate change adaptation and mitigation: Challenges and opportunities for food security. 2008. Rome, Food and Agricultural Organisation.

[2] IPCC Working Group II. Working Group II Contribution to the Intergovernmental Panel on Climate Change, Fourth Assessment Report Climate Change 2007: Climate Change Impacts, Adaptation and 
Vulnerability, Summary for Policymakers. 2007. Geneva, Intergovernmental Panel on Climate Change.

[3] Oxfam. Climate Alarm: Disasters increase as climate change bites. 2007. London, Oxfam.

[4] Z. Chafe, Weather-related disasters climb, Vital Signs, (2008) 44-45.

[5] Swiss Agency for Development and Cooperation. Disaster risk reduction in the project cycle management: A tool for programme officers and project managers. 2007. Geneva, Swiss Agency for Development and Cooperation.

[6] Caribbean Development Bank, Sourcebook on the integration of natural hazards into the environmental impact assessment process, Caribbean Development Bank, Barbados 2004.

[7] ProVention Consortium. Tools for mainstreaming disaster risk reduction: Project cycle management. 2007. Geneva, ProVention Consortium Secretariat.

[8] USAID. Adapting to climate variability and change: A guidance manual for development planning. 2007. Washington D.C., USAID.

[9] Larsen, P. B. and Springer, J. Mainstreaming WWF principles on indigenous peoples and conservation in project and programme management. 2008. Gland and Washington D.C., WWF.

[10] DEAT (Department of environmental Affairs and Tourism). Long Term Mitigation Scenarios Strategic Options for South Africa. 2007. Pretoria, Government Printer. 